\title{
UM ESTUDO SOBRE A LIDERANÇA SITUACIONAL E AS SUAS CONTRIBUIÇÕES PARA O DESENVOLVIMENTO DAS ORGANIZAÇÕES
}

\author{
Lucas Teixeira Grassi RAMOS ${ }^{1}$ \\ Marcelo Roberto Barroso CORRÊA ${ }^{2}$ \\ Sheldon William SILVA \\ Márcio de Oliveira PEREIRA ${ }^{4}$ \\ Poliana Tomaz LEMES 5 \\ Sérgio Ricardo MAGALHÃES ${ }^{6}$
}

\footnotetext{
${ }^{1}$ Bacharel em Administração, UNIS-MG. administracao_comex@ unis.edu.br

${ }^{2}$ Especialista em Administração - foco em RH (Universidade José do Rosário Vellano). Professor no UNIS-MG. mrcorrea@uai.com.br

${ }^{3}$ Mestre em Administração (FPL), Professor no UNIS-MG. sheldonwilliamsilva@gmail.com

${ }^{4}$ Mestre em Administração (FACECA), Professor no UNIS-MG. Márcio.pereira@unis.edu.br

${ }^{5}$ Especialista em Docência na Educação a Distância (UNIS), Professora no UNIS-MG. Poliana.lemes@unis.edu.br

${ }^{6}$ Doutor em Engenharia Biomédica (IP\&D), Professor na UNINCOR-MG. sergio.magalhaes@ unincor.edu.br
}

Recebido em: 09/04/2016 - Aprovado em: 28/06/2016 - Disponibilizado em: 30/07/2016

\begin{abstract}
RESUMO
O presente trabalho possui como objetivo apresentar e justificar o quão favorável é para uma organização investir em seu capital intelectual, principalmente no que tange à essência de toda a gestão e ao norteamento das operações em função da visão, missão e valores organizacionais que só os gestores possuem. Para alcançar o objetivo proposto utilizou-se da pesquisa bibliográfica exploratória com consultas a livros, revistas e sites especializados, além de artigos científicos. Evidenciando o que é notório nas organizações de sucesso: presença de uma liderança sadia e eficaz. É possível ainda, explicitar que a influência de uma gestão que exerça liderança e seja tão flexível quanto o ambiente no qual está inserido é um importante exponencial na linha produtiva. Como resultados, infere-se uma perspectiva organizacional de resultados por meio da Liderança Situacional.
\end{abstract}

Palavras-chave: Capital Intelectual; Estilo de liderança; Liderança Situacional.

\section{ABSTRACT}

This work has the purpose to present and justify how favorable is for an organization to invest in its intellectual capital especially regarding the essence of the entire management and guid of operations due to the vision, mission and organizational values that only managers possess. Highlighting what is still evident in its successful organizations: the presence of a good and effective leadership. You can also explain the influence of a leader who exercises leadership and still be as flexible as the environment which it is inserted, it's an important exponential in the production line. These can be done by the Situational Leadership.

Keywords: Intellectual Capital, Leadership Style, Influence of a Leader, Situational Leadership.

\section{INTRODUÇÃO}

Com a concorrência cada vez mais acirrada, as empresas modernas têm se valido de estratégias que atinjam aos objetivos propostos de maneira mais rentável e menos dispendiosa. Uma saída encontrada para promover tal panorama, foi o investimento em seu capital intelectual que, segundo conceito de Stewart (1998, p. 13), “constitui a matéria 
intelectual - conhecimento, informação, propriedade intelectual, experiência - que pode ser utilizada para gerar riqueza". A organização contemporânea entendeu que seu capital humano é promotor e desenvolvedor organizacional, tanto quanto suas máquinas e estruturas. Porém, mais recentemente, as organizações encontraram uma forma de fazer isso sem precisar de grandes investimentos. Nota-se que o incentivo ao líder é o catalisador mais barato na hora de garantir resultados rentáveis através do desenvolvimento de toda equipe/liderados e que isso poderia ser facilmente executado através do aperfeiçoamento dos estilos de liderança.

No entanto, como as organizações se encontram em um ambiente aberto e, em consequência, suscetível às exigências e mudanças de um mercado cada vez mais dinâmico, explicitou-se a necessidade de se promover também aos estilos de liderança essa intensa necessidade de adaptabilidade vigente agora no mercado. Com isso, nasceu a Teoria da Liderança Situacional constituída da adaptação do líder ao ambiente mercadológico ao qual a organização está inserida. A pesquisa tem, portanto, a missão de demonstrar a aplicabilidade da liderança situacional e de sua forma de liderar atrelando técnicas de análise da situação e posterior adaptabilidade ao meio na intenção final de atingir os objetivos organizacionais tornandose uma empresa eficiente e eficaz. Procura ainda responder como este estilo de liderança poderá desenvolver as organizações começando por seus líderes.

Desta forma, intenta-se demonstrar se há ou não um modelo de liderança que seja satisfatório a todos os interesses organizacionais principalmente no que tange à tomada de decisões. E responder se é possível desenvolver a organização, através do desenvolvimento e aperfeiçoamento do líder. Outro ponto relevante a ser discutido diz respeito à análise das situações contextuais em que a organização está inserida uma vez que essas mesmas organizações fazem parte de um sistema aberto e que por consequência está sujeito às intervenções do meio externo.

\section{A LIDERANÇA SITUACIONAL NAS ORGANIZAÇÕES}

\section{O capital humano e intelectual nas organizações}

Em mudanças constantes e na busca cada vez mais agressiva pelo máximo de resultados que utilizem o mínimo de recursos possíveis, as organizações têm se valido ainda mais de seu capital humano - o que antes era visto apenas como gerador de riquezas, não sendo, portanto, necessários seu desenvolvimento intelectual e sua especialização. Agora é utilizado como ferramenta que irá, não só intensificar a linha 
produtiva, mas também será fundamental para o bom êxito financeiro empresarial.

Gerschuny conceitua Capital Humano como:

[...] do mesmo modo que o comportamento de uma empresa é determinado pela natureza e localização de sua planta física ou "capital", o do indivíduo é determinado pelo seu "capital humano". Trata-se de um conjunto fixo de habilidades, experiência e posição social (e geográfica) que... determina a ação individual (GERSCHUNY, 2000, p. 85-6).

Gerschuny (2000) complementa ainda “[...] Habilidades atuais, experiência, qualificações e conexões sociais constituem o capital humano economicamente relevante do indivíduo e determinam suas opções de atividade econômica". Porém, como parte integradora do Capital Humano, vem o Capital Intelectual que será uma das medidas de investimento que se configurará em treinamento e/ou aperfeiçoamento dos estilos de liderança de seus administradores.

Segundo Antunes e Martins (2002)

[...] Capital Intelectual é o somatório do conhecimento proveniente das habilidades aplicadas (conhecimento tácito) dos membros da organização com a finalidade de trazer vantagem competitiva, materializado em bons relacionamentos com clientes e no desenvolvimento de novas tecnologias. (ANTUNES E
MARTINS, 2002, p. 4154)

Com isso, a organização terá condições de atingir suas metas e objetivos tornando-se bem-sucedida. Segundo definição de Hersey e Blanchard (1986, p. 428), a organização bem-sucedida "tem uma característica principal que a distingue das organizações malsucedidas: uma liderança dinâmica e eficaz".

A gestão organizacional compreendeu que para uma empresa ser eficiente e eficaz, antes de mais nada, ela precisa ter bons gestores e que a configuração de um bom gestor se dá quando o mesmo entende e usa suas características pessoais na constituição de um estilo de liderança. Entretanto, essa definição de estilo de liderança dependerá, não só da análise das competências de seus liderados, como também do nível de maturidade/envolvimento com os propósitos da empresa, realocando competências e grau de envolvimento em benefício da organização. Outra qualidade percebida e reconhecida pela gestão organizacional é que, em muitos casos, essa liderança tanto pode ser nata quanto desenvolvida.

\section{CONCEITO DE LIDERANÇA}

Hunter define liderança como sendo "[...] a habilidade de influenciar pessoas para trabalharem entusiasticamente visando atingir 
aos objetivos identificados como sendo para o bem comum. " (HUNTER, 2004, p. 25)

Já segundo Chiavenato (1994, p. 147), o conceito de liderança é definido como:

[...] um fenômeno social que ocorre exclusivamente em grupos sociais. Ela é definida como uma influência interpessoal exercida em uma dada situação e dirigida pelo processo de comunicação humana para a consecução de um ou mais objetivos específicos.

(CHIAVENATO, 1994 p. 147)

Terry (1999, p. 747), explica que liderança é "a atividade de influenciar pessoas fazendo-as empenhar-se voluntariamente em objetivos de grupo". Já Tannenbaum, Weschler e Massarik (1961, p. 476) conceituam liderança como "influência interpessoal exercida numa situação e dirigida, através do processo de comunicação, para a consecução de objetivos específicos”.

Liderança é a capacidade de convencer alguém a fazer algo que resulte em algum benefício. No meio organizacional, será a capacidade de influenciar o subordinado a realizar uma atividade orientada para o bem organizacional. O gestor fará isso através do uso das competências de seus subordinados realocadas em função de um bom êxito nas operações. Vale ainda esclarecer, que embora confuso para muitos, há uma sutil distinção entre liderança e poder. Enquanto a liderança surge da capacidade (como já afirmado) de influenciar alguém por

vontade própria a fazer algo, o poder se configura também nessa capacidade, porém, sob a coerção e/ou obrigação de realizar tal tarefa. Com isso, afirma-se que a liderança é uma característica muito mais interpessoal e social do que o poder.

\section{Liderança inata $\mathrm{x}$ liderança desenvolvida}

Ainda há uma pequena argumentação de como se dá esse processo de formação da liderança. Alguns teóricos defendem a ideia de que o espírito de liderança é algo inato e depende mais de fatores pessoais $\mathrm{e}$ experiências sendo alguns traços de personalidade, indispensáveis na formação de um bom líder tais como: fatores emocionais e físicos, características pessoais e intelectuais.

O gestor deveria estar necessariamente em conformidade com os objetivos, missão, bom estabelecimento de prioridades, facilidade em delegar responsabilidade e solucionar problemas e, por fim, orientar e supervisionar pessoas. Já teóricos mais modernos, defendem a ideia de que a liderança é algo que se desenvolve através do incentivo a certos traços de personalidade que embora possam ser natos - são aptos à progressão.

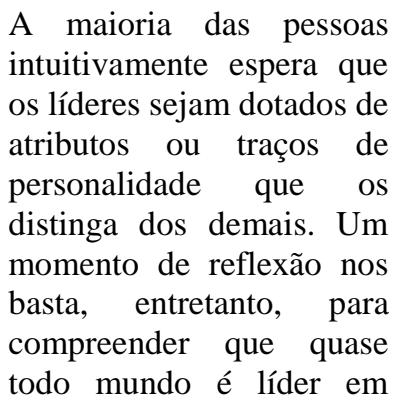




\begin{abstract}
alguns grupos e liderado em outros, e que existem muito poucas pessoas que sejam líderes o tempo todo, ou mesmo durante a maior parte do tempo. Há relativamente poucos que nunca foram líderes. Portanto, apenas fatores de personalidade não bastam para determinar quem se tornará um líder, tanto mais que alguns dos fatores que isso determinam estão completamente fora do controle do indivíduo. (FIEDLER, 1981, p. 11)
\end{abstract}

Vale ressaltar que, como a liderança está inserida em uma rotina suscetível a intervenções do meio, era preciso contextualizar essas características na tomada de decisões e gestão de pessoas através da adequação da liderança conforme a necessidade de adoção de alguma peculiaridade em específico para a resolução de determinado problema que careça de tal atitude.

Assim, pois, a liderança deve ser concebida em termos de interação de variáveis, que se encontram em constante alteração. $\mathrm{O}$ fator de mudança é especialmente característico

da situação...é claro, portanto, que uma análise adequada do problema de liderança envolve não só um estudo acerca de líderes, mas também de situações. (STOGDILL, 1948, p. 64).

Como principais características constituintes de um bom líder, pode-se citar: criatividade, inovação, empreendedorismo, responsabilidade e capacidade de lidar com pessoas. Ou seja, atitudes que, quando estimuladas, produzem um bom gestor capaz de liderar.

\section{Estilos de liderados: comparações entre a Teoria X e a Teoria Y}

Orientando-se agora para a capacidade de identificar modelos de liderados, pode-se dar destaque para as pesquisas de McGregor (1960) que defendia que existem apenas duas classificações de colaboradores no meio organizacional. Uma identifica o trabalhador como preguiçoso e com restrições ao trabalho, a outra seria a classificação de um trabalhador responsável e desejoso de trabalhar. Ele chamou a essas teorias de Teoria X e Teoria $\mathrm{Y}$, respectivamente.

Como a Teoria $\mathrm{X}$ afirmava que $\mathrm{o}$ trabalhador era essencialmente preguiçoso e em consequência evita sempre o trabalho e as responsabilidades, "O trabalho é em si mesmo desagradável para a maioria das pessoas" (McGregor, 1999, p.13). Surge à necessidade de um líder autoritário e controlador para supervisionar e pressionar esse mesmo trabalhador. A palavra de ordem do líder nesta teoria deve ser coerção.

Já na Teoria $\mathrm{Y}$ em antítese a $\mathrm{X}$, defende a ideia de que este segundo modelo de trabalhador é configurado como sendo responsável e altamente competente realizando seus trabalhos por prazer e desejo de desenvolver a organização. Características como criatividade, organização e boa vontade 
são amplamente incentivadas. No entanto, é preciso que o gestor dê condições de se desenvolverem tais características.

"O trabalho é tão natural como o lazer, se as condições forem favoráveis" (McGregor, 1999, p.15). Configurado os dois perfis mais comuns de trabalhadores, vale agora ressaltar os tipos de liderança.

\section{Principais estilos de liderança}

A partir de estudos coordenados por Kurt Lewin, Lippitt e White (1939) chegou-se à conclusão de que havia três principais e mais conhecidos estilos de liderança. São eles: autocrática, liberal e democrática. A primeira, a autocrática, vem a ser o estilo de líder no qual apenas ele é o tomador de decisões sem qualquer participação da equipe. Dentre as características principais, este estilo de liderança apresenta um líder pessoal e dominador nos elogios e críticas exercendo a todo instante sua autoridade. Já a segunda, a liberal, configura-se como uma liderança voltada para a total liberdade na tomada de decisões por parte do líder. O grupo é quem define e aplica as decisões. Como características deste estilo de liderança, o líder apresenta total passividade só exprimindo suas opiniões quando perguntado - suas orientações são baseadas em comentários e sugestões.

Por fim, a liderança democrática definida como sendo apresentado maior debate na tomada de decisões através da equipe estimulada e assistida pelo líder. Configurando o líder, tem-se um gestor mais objetivo em suas decisões, elogios e críticas, além de um estimulador da equipe. Essas eram as três grandes definições de líderes e estilos de liderança mais comuns. No entanto, mais recentemente, surgiu um novo modelo: a liderança situacional.

\section{Conceito de liderança situacional}

A liderança situacional, conforme apresentou Hersey e Blanchard (1986), está embasada na relação de líder e liderado, norteando-se sempre para a mensuração e o desenvolvimento da maturidade do colaborador em vista da obtenção de bons resultados em consonância com os objetivos organizacionais. Como o meio organizacional está inserido em um sistema aberto que, segundo Chiavenato (2003, p. 233):

Tem comportamento
probabilístico e recebe
influência ao mesmo
tempo em que influencia o
meio externo, pois
apresenta relação de
intercâmbio com o
ambiente no qual está
inserido, por meio de
inúmeras entradas e saídas.
Por isso, os sistemas
abertos são adaptativos,
reajustando-se
constantemente ao meio.
(CHIAVENATO, 2003, p.
233).

Desta forma, justifica-se a defensiva de que um bom líder será justamente aquele 
que melhor se insere nesta adaptabilidade do meio e que às constantes mudanças são importantes para se configurar como uma liderança saudável em que o liderado irá, não só reconhecer a liderança de seu gestor, como também se moldar de acordo com as mudanças do meio.

\section{O perfil do gestor na liderança situacional}

Em linhas gerais, segundo Hersey e Blanchard (1986), o perfil do Gestor do Tipo Situacional é aquele perfil orientado em adequar a ação em vista da situação. Ele irá optar por qual atitude deverá ser tomada analisando se sua postura se norteará pelo perfil democrático, autoritário ou liberal, podendo inclusive ser adotados de forma conjunta conforme os diferentes graus de envolvimento que a situação exigir. A essa capacidade de variação, os autores chamaram de Faixa de Estilo.

Com essa adoção de estilo acordado com a demanda, o gestor garante, não só a assertividade de suas ações, mas também, ele incentiva o seu administrando a se desenvolver em consonância com as ocorrências, com isso há a liberdade e a capacidade de crescimento garantindo bons resultados no somatório do capital intelectual da empresa. Os autores ainda afirmam que os líderes flexíveis são aqueles com o maior potencial de serem eficazes e que o uso de vários estilos na mesma situação (faixa de estilo) não é garantia de bons resultados tanto quanto a capacidade de adaptabilidade, ou seja, enfatiza muito mais a flexibilização do que o norteamento para um dos três estilos.

\section{Relação entre líder e liderado na liderança situacional}

Aprofundando ainda mais na teoria de Hersey e Blanchard (1986), pode-se ainda citar os três pilares onde estão embasadas as relações entre líderes e liderados. São eles: inter-relação entre a quantidade despendida de orientação que o líder possibilita, o nível do relacionamento entre superior e subordinado e o grau de maturidade por parte do subordinado. Em que se pode entender como "maturidade", a capacidade que o subordinado tem de entender a problemática e sua importância e grau de envolvimento dentro do processo de resolução do problema.

A partir da gestão dessas três ferramentas de liderança situacional é que o líder terá condições de mensurar dentro de sua equipe quais membros são maduros o suficiente, quais são confiáveis e quais necessitam de mais ou menos supervisão. Com isso, ele terá condições de otimizar tempo alocando as pessoas certas nas tarefas corretas. E que, ainda segundo Hersey e Blanchard (1986, p. 478) "Quanto mais os gerentes adaptarem seu estilo de comportamento de líder no sentido de atender à situação específica e às necessidades dos 
seus subordinados, tanto mais eficazes serão na consecução dos objetivos pessoais e organizacionais. "

A teoria se complementa defendendo, inclusive a ideia que o líder com seu comportamento adaptativo, não deve adotar o “melhor" estilo de liderança, mas o mais eficaz para alguma situação em específico. Para tanto deve-se levar em conta:

\section{[...] grau em que a situação proporcione controle $\mathrm{e}$ influência ao líder, isto é, a extensão em que o líder é, ou se sente, capaz de alcançar os resultados que deseja. Estreitamente relacionada com isto está a questão da previsibilidade. Em que medida pode o líder prever o que ocorrerá quando der uma ordem, quando optar por um método de trabalho em lugar de outro, quando recompensar ou punir. (FIEDLER, 1981, p. 57).}

A proposta é que os variados comportamentos de liderança podem ser classificados como eficazes ou ineficientes, de acordo com as exigências da situação. A essa classificação, Fiedler (1960, p. 13) chamou de Modelo Contingencial de liderança. De acordo com o modelo Contingencial proposto, três são as variáveis situacionais que irão classificar uma determinada situação favorável ou não. São elas:

1) Relação entre líder e liderados;

2) O grau de complexidade da ação a ser praticada;

3) A autoridade que o líder deve exercer.

A posterior classificação, Fiedler deu o nome de Favorabilidade de uma Situação sendo, portanto, classificada como "o grau em que a situação permite ao líder exercer sua influência sobre seu grupo" (Fiedler, 1967, p. 13).

Por este modelo ainda, pode-se afirmar que, como não há nada que seja absoluto nas organizações, uma vez que as mesmas estão inseridas em meio aberto e suscetíveis às variáveis deste mesmo meio. Justificando, portanto, que não há um estilo de liderança perfeito e somente a partir da análise situacional será possível melhor definir, naquele momento, qual estilo de liderança adotar e em qual grau de complexidade.

\section{METODOLOGIA}

A metodologia utilizada foi a pesquisa bibliográfica exploratória com consultas a livros, revistas especializadas no assunto e acessos a sites relacionados ao tema, além de conversas com mestres, profissionais experientes da área de $\mathrm{RH}$.

Koche (1997, p. 122) afirma que esse tipo de pesquisa,

Tem a finalidade de
ampliar o conhecimento na
área, de dominar o
conhecimento para depois
utilizá-lo como modelo
teórico que dará
sustentação a outros
problemas de pesquisa e 
para descrever e sistematizar o estado da arte na área estudada. (KOCHE, 1997, P. 122).

Gil (2007, p. 50) ainda completa com as vantagens da pesquisa bibliográficas:

\begin{abstract}
A principal vantagem da pesquisa bibliográfica reside no fato de permitir ao investigador a cobertura de uma gama de fenômenos muito mais ampla do que aquela que poderia pesquisar diretamente. Esta vantagem se torna particularmente importante quando o problema de pesquisa requer dados muito dispersos pelo espaço. (GIL, 2007, p. 50).
\end{abstract}

Esta pesquisa - teve, no entanto - seu embasamento bibliográfico orientado pela pesquisa teórica e conceitual de Capital Humano, Capital Intelectual, Conceito de Liderança, Estilos de Liderança, Comparativo entre as teorias X e Y, Relações de Líderes e Liderados e a Liderança Situacional no meio Organizacional como ferramenta catalisadora na eficiência e eficácia das organizações.

\section{ANÁLISE E INTERPRETAÇÃO DE DADOS}

Desta forma, pretende-se através do exame crítico aos perfis comumente adotados por líderes e liderados nos vários Estilos de Liderança demonstrar abrangência da Liderança Situacional.

Após análise comparativa entre os diferentes tipos de Estilos de Liderança pode- se entender que não existe apenas um estilo a ser adotado a todo e qualquer momento, visto que para se chegar a um melhor estilo alguns fatos precisam ser ponderados; tais como: entendimento e posicionamento crítico por parte do gestor em função do ambiente em que a organização está inserida, uma vez que esse mesmo ambiente é aberto e suscetível às mudanças do meio; tipos de problema advindos do ambiente e qual a melhor forma de prover e alocar recursos materiais e de pessoal visando a resolução mais imediatista possível dos mesmos problemas; saber ainda qual o nível de envolvimento dos colaboradores e como aproveitar capacidades pessoais em função do desenvolvimento da organização. Neste último ponto, retoma-se a problemática inicial, ao mesmo tempo que a soluciona: como estimular o desenvolvimento das organizações através da Liderança Situacional minimizando custos e prazos.

O gestor terá condições de fazer isso através de análises importantes, como: exame crítico das minucias do problema; olhar analítico da situação; percepção de quais colaboradores melhor seriam aplicados na tentativa de se resolver o problema.

A partir desta investigação o gestor poderá optar por qual Estilo de Liderança (autocrático, democrático e liberal) melhor se adequa a situação. Podendo, inclusive, alternar entre os três principais tipos. 


\section{CONSIDERAÇÕES FINAIS}

Em vista das teorias apresentadas entende-se que para a obtenção rápida, eficaz e eficiente dos resultados esperados pelo meio organizacional é necessário certo grau de investimento. E, que uma das alternativas empresarias para se investir e obter resultados assertivos, será a investidura no Capital Humano. Porém, de forma mais específica, na formação de líderes que sejam capazes de se adaptar ao meio respondendo ao mesmo de forma mais contextualizada com suas exigências mercadológicas.

A escolha de investimento primeiramente nos líderes - advém da premissa de que os mesmos são os responsáveis por orientar, capitar, incentivar, alocar e mensurar o grau de envolvimento das equipes/liderados. Porém, para tanto, o líder precisará desenvolver aptidões específicas de um bom líder bem como a capacidade de avaliar as diversas situações. Desta forma ele estará garantindo o sucesso mercadológico da organização.

Com isso, afirma-se que a melhor estruturação do estilo de liderança será, neste caso, a nomeada Liderança Situacional que versa, basicamente, sobre a adaptação deste mesmo líder e seu estilo de liderança de acordo com o conveniente em dada situação. Essa implantação de tal estilo de liderança só é possível levando-se em conta a afirmativa que todos são líderes em potencial uma vez que as principais características esperadas de um bom líder são aptas a progressão.

No entanto, por se tratar de teorias fundamentadas em Gestão de Pessoas e, por essa mesma razão, lidar diretamente com os capitais Humano e Intelectual da organização, uma pesquisa de campo seria uma alternativa interessante para comprovar a eficiência da Liderança Situacional. Outro ponto de grande interesse e que enriqueceria a pesquisa seria a aplicação de um questionário entre líderes e liderados onde procuraria medir a preferência de estilo de liderança de ambas as partes na hora da tomada de uma decisão. Com isso, procuraria provar que não há um estilo fixo de se liderar e sim uma adaptabilidade ao meio extremamente conveniente à resolução dos problemas.

\section{REFERÊNCIAS}

AFRÂNIO ALBERTASSI. Comportamento do Líder e a Influência na Motivação dos Liderados. Rio de Janeiro: Instituto a Vez do Mestre, 2010. Disponível em:

<http://www.avm.edu.br/docpdf/monografias _publicadas/g200518.pdf>. Acesso em: 03 maio 2014.

ANTUNES, M. T. P. MARTINS, E. Capital intelectual: verdades e mitos. Revista de Contabilidade \& Finanças da USP - FEA - 
Departamento de Contabilidade e Atuaria. São Paulo - SP, ano XIII, n 29, p.41-54, mai/agos.2002.

BANOV, Márcia Regina. Psicologia no Gerenciamento de Pessoas. 2. ed. São Paulo: Atlas, 2011, 118 p.

BIP.KNOWLEDGE; Liderança Situacional. Disponível em:

<http://knowledge.othink.com/index.php/pess oas/89-lideranca-situacional $>$. Acesso em: 03 maio 2014.

CANDELORO, Raúl. As 10 características dos grandes líderes. Negócios, São Paulo, 2009.

CARISSIMI , Édiner Antônio. Liderança contingencial-situacional. Recursos

Humanos, Santa Catarina, 2008, n.1. Disponível em:

<http://www.rh.com.br/Portal/Lideranca/Arti go/5110/lideranca-contingencialsituacional.html\#conteudo_base>. Acesso em: 22 maio 2014.

CHIAVENATO, Idalberto. Introdução à teoria geral da Administração: uma visão abrangente da moderna administração das organizações. 7. ed. Ver. E atual. - Rio de Janeiro: Elsevier, 2003 - 2 ${ }^{\text {a }}$ Reimpressão. 692 p.

Gerenciando Pessoas. 2. ed. São Paulo: Makron Books, 1994 p. 147.

CLAUDIA LUCIA DOS SANTOS ALVES. Liderança nas Organizações. Rio de Janeiro: Exame, 2005. Disponível em: <http://www.avm.edu.br/docpdf/monografias _publicadas/k207884.pdf $>$. Acesso em: 10 maio 2014.

GERSCHUNY, J. Changing times: work and leisure in postindustrial society. Oxford: Oxford University Press, 2000 p. 856.

\section{GIL, A. C. Como elaborar projetos de} pesquisa. São Paulo: Atlas, 2007 p. 50.
TERRY, George R. Princípios da

Administração. 1. ed. Mexico: Compañía Editorial Continental, 1999, 747 p.

MCGREGOR, Douglas. The Human Side of Enterprise. 1. Ed. Detroit: McGraw-Hill, 1960, $256 \mathrm{p}$.

O lado humano da empresa.

Tradução: Margarida Maria C. Oliva, 3 ed. São Paulo: Martins Fontes, 1999 p. 15.

HERSEY, Paul; BLANCHARD, Kenneth H. Psicologia para Administradores: A Teoria e as Técnicas da Liderança Situacional. 8. ed. São Paulo: Editora Pedagógica e Universitária Ltda, 1986, 428 p.

HUNTER J.C. O Monge e o executivo: uma história sobre a essência da liderança. 8. ed. Rio de Janeiro: Sextante; 2004 p. 25.

IB - COACHING; Instituto Brasileiro de Coaching; O que é Liderança Situacional. Disponível em: < http://www.ibccoaching.com.br/tudo-sobrecoaching/lideranca-e-motivacao/o-que-elideranca-situacional/>. Acesso em: 09 jun. 2014

KOCHE, José Carlos. Fundamentos de metodologia científica: teoria da ciência e prática de

pesquisa. 14.ed. Petrópolis: Vozes, 1997 p. 122.

Lewin, K., R. Vlippitt e R. K. White, Patterns of agressive behavior in experimentally created social climates, Journal of Social Psychology 10 (1939): 271-99.

MARTINS, Rogério. Liderança é Nata ou Pode ser Desenvolvida? Recursos Humanos, Santos, 2014, n. 1. Disponível em:

<http://www.administradores.com.br/artigos/c arreira/lideranca-e-nata-ou-pode-serdesenvolvida/76509/>. Acesso em:13 jun. 2014.

NATHALY BISPO. Liderança situacional e a teoria de Hersey e Blanchard. Gestão e RH, 2013, n. 2. Disponível em: < 
http://www.catho.com.br/carreirasucesso/gestao-rh/o-lider-situacional>.

Acesso em: 13 jun. 2014.

PERIARD, Gustavo.

sobreadministracao.com. Tudo sobre as

Teorias X e Y de Douglas McGregor, 2011, n. 3. Disponível em: <

www.sobreadministracao.com/tudo-sobre-asteorias-X-e-y-de-douglas-mcgregor/> . Acesso em: 04 maio 2014.

PORTAL GESTÃO; portal-gestão.com; O

Modelo Hersey-Blanchard: Como Liderar Eficazmente os seus Colaboradores.

Disponível em: <http://www.portalgestao.com/item/7001-o-modelo-herseyblanchard-como-liderar-eficazmente-os-seuscolaboradores.html>. Acesso em: 02 jun. 2014.

TANNENBAUM Robert; WESCHLER Irving R.; MASSARIK Fred. Leadership and Organization: A Behavioral Science Approach. 1 e. d. New York: McGraw-Hill $1961.476 \mathrm{p}$.

STEWART, T. A. Capital Intelectual - A nova vantagem competitiva das empresas. 10a ed. Rio de Janeiro: Campus, 1998.

STOGDILL, R. M., Personal factors associated with leadership: A survey of the literature, Journal of Psychology 25 (1948): p. 64.

TAYLOR, Frederick Winslow. Princípios de Administração Científica. 8. ed. São Paulo: Atlas, 2010, 112 p.

VENTURA, André Martin Marquez. artigos.com; Liderança que Pode ser Desenvolvida. São Paulo, 2009, n. 1. Disponível em:

<http://www.artigos.com/artigos/sociais/admi nistracao/lideranca/lideranca-que-pode-serdesenvolvida-6008/artigo/\#.U6cEthso_mR>. Acesso em: 16 jun. 2014. 